\title{
Effects of cadmium exposure on the growth, photosynthesis, and antioxidant defense system in two radish (Raphanus sativus L.) cultivars
}

\author{
J. XIN, X.H. ZHAO, Q.L. TAN, X.C. SUN, Y.Y. ZHAO, and C.X. HU+ \\ Hubei Provincial Engineering Laboratory for New Fertilizers/Research Center of Trace Elements/Key Laboratory \\ of Arable Land Conservation (Middle and Lower Reaches of Yangtze River), Ministry of Agriculture, Huazhong \\ Agricultural University, Wuhan 430070, China
}

\begin{abstract}
Radish is representative root vegetable; its edible parts are directly in contact with Cd-contaminated fields. Two radish cultivars (H4 and L19) with different resistance to $\mathrm{Cd}$ were selected to compare their growth, photosynthesis, and antioxidant systems. Our results revealed that $\mathrm{H} 4$ was more sensitive to Cd pollution than L19; a significant decrease in the biomass of $\mathrm{H} 4$ was observed at higher $\mathrm{Cd}$ concentrations. With increasing $\mathrm{Cd}$ concentrations, the net photosynthetic rate, effective quantum yield of PSII photochemistry, electron transport rate through PSII, and photochemical quenching were all lowered, however, reductions were more obvious in H4 compared to L19. Further, both peroxidase and catalase activities of L19 were remarkably higher than those of H4. Smaller reductions in ascorbic acid and no obvious changes in glutathione were observed in the leaves of H4. These results suggest that the differences in Cd tolerance could be attributed to the distinct photosynthetic parameters and differences in antioxidant system between L19 and H4.
\end{abstract}

Additional key words: antioxidant enzyme; cadmium stress; chlorophyll fluorescence; gas exchange; hyperaccumulator plant.

\section{Introduction}

Cadmium $(\mathrm{Cd})$ has emerged as one of the most serious environmental pollutants due to its widespread occurrence and toxicity. It has been reported that anthropogenic inputs, primarily due to smelting, fossil fuel combustion, and the application of sewage sludge and phosphate fertilizers, have led to the excessive accumulation of $\mathrm{Cd}$ in soils (Grant 2011). Although Cd is a nonessential element, it is readily taken by plants and subsequently causes extreme damage to their physiology and biochemistry, including the inhibition of photosynthesis, increased membrane permeability, and adverse effects on protective enzyme activities (Hashem 2014, Pereira de Araújo et al. 2017).

Photosynthesis is an integral part of basic plant physiology. It allows energy from sunlight to be converted into a storable form, usually glucose, which plants use to grow and thrive. In general, photosynthesis is negatively impacted by $\mathrm{Cd}$ in various ways, including damage of various components in photosynthetic machinery (Parmar et al. 2013, Pereira de Araújo et al. 2017), inhibition of photochemical reactions (Dias et al. 2013, Xue et al. 2014, Mesnoua et al. 2016), disturbance of enzymatic activities in the Calvin cycle, and disorganization of the inherent reactive oxygen species (ROS) balance of chloroplasts (Pospíšil 2012, 2014). Wang et al. (2014) and Daud et al. (2013) demonstrated that Cd induced the inhibition of chlorophyll (Chl) biosynthesis, and distorted the chloroplast ultrastructure and $\mathrm{Mg}^{2+}$ substitution of both $\mathrm{Chl} a$ and $b$, thereby leading to a reduction in the Chl content. In recent years, the technique of $\mathrm{Chl}$ fluorescence has become a powerful tool for a quick and nonintrusive evaluation of photosynthetic performance in vivo and for identification of possible causes of changes in photosynthesis and plant performance (Maxwell and Johnson 2000, Baker 2008). Xue et al. (2014) have reported that more excessive excited energy was produced in the young leaves than in the mature leaves, which further damaged the photosynthetic apparatus. Chloroplasts are the most powerful ROS sources in plant tissues (Foyer et al. 1994). It has been reported that when ROS are formed in excess, the oxidation of cellular biomolecules by ROS might produce oxidative damage to pigments, proteins, and lipids in thylakoid membranes, as well as the reduction of photosynthesis, which can eventually lead to the plant death (Pospíšil 2012, 2014). Plants have developed ROS-scavenging systems that are

$\overline{\text { Received }} 21$ February 2018, accepted 22 October 2018.

${ }^{+}$Corresponding author; e-mail: hucx@mail.hzau.edu.cn

Abbreviations: AsA - ascorbic acid; CAT - catalase; $C_{\mathrm{i}}$ - intercellular $\mathrm{CO}_{2}$ concentration; ETC - electron transport chain; ETR - electron transport rate through PSII; $g_{s}$ - stomatal conductance; GSH - reduced glutathione; MDA - malondialdehyde; POD - peroxidase; $\mathrm{q}_{\mathrm{N}}$ - nonphotochemical quenching; $\mathrm{q}_{\mathrm{p}}$ - photochemical quenching; ROS - reactive oxygen species; SOD - superoxide dismutase; $\Phi_{\text {PSII }}$ - effective quantum yield of PSII photochemistry.

Acknowledgements: The work was funded by the National Natural Science Foundation of China (Program No. 41271275). We gratefully acknowledge Professor Ron McLaren (Emeritus Professor of Environment Soil Science, Lincoln University) for helpful advice and revision on this manuscript. 
composed of enzymatic and nonenzymatic antioxidants, such as superoxide dismutase (SOD), peroxidase (POD), catalase (CAT), reduced glutathione (GSH), and ascorbic acid (AsA) (Namdjoyan et al. 2014, Xu et al. 2016). The response of plant scavenging systems to $\mathrm{Cd}$ is variable, not only among plant species, but also in genotypes within the same species. For Lolium perenne L. and the metalaccumulators, Thlaspi caerulescens and Brassica juncea, POD, CAT, and SOD activities were enhanced after exposure to $\mathrm{Cd}$, whereas CAT activity declined rapidly; SOD and POD activities were enhanced after the Cd exposure in a non-accumulator plant (Nicotiana tabacum) (Luo et al. 2011, Xu et al. 2016). Furthermore, Wu et al. (2004) reported that the relatively lesser reductions of GSH and AsA were observed in ZAU 3, which is a Cdtolerant genotype.

Radish is an important annual or biennial root vegetable crop of the Brassicaceae family cultivated worldwide (Wang and $\mathrm{He}$ 2005). A risk of $\mathrm{Cd}$ contamination in the roots of this plant is becoming of a great concern. Radish leaves, which are important nutritional organs, provide nutrients for plants via photosynthesis. Although previous experiments have focused primarily on responses of photosynthetic and antioxidant systems to $\mathrm{Cd}$ exposure, there are few reports combining these two systems in order to examine systematically the effects of Cd stress. The objectives of this work were to examine and compare the growth, photosynthesis, and antioxidant systems of the two radish cultivars of a low and high Cd tolerance, which might contribute to a better understanding of the biological mechanisms involved under Cd stress.

\section{Materials and methods}

Plant material, growth, and treatments: Two radish (Raphanus sativus L.) cultivars, H4 (less Cd-tolerant cultivar) and L19 (highly Cd-tolerant cultivar), were used in this study. The soil was collected from the surface layer $(0-15 \mathrm{~cm})$ of the cultivated soil in Huazhong Agricultural University, Wuhan, China. The soil was yellow brown, with the following characteristics: $\mathrm{pH} 7.12,52.33 \mathrm{~g}$ (available N) $\mathrm{kg}^{-1}, 7.96 \mathrm{mg}$ (organic C) $\mathrm{kg}^{-1}, 16.57 \mathrm{mg}$ (available P) $\mathrm{kg}^{-1}$, $193.48 \mathrm{mg}$ (available $\mathrm{K}$ ) $\mathrm{kg}^{-1}, 0.06 \mathrm{mg}$ (total Cd) $\mathrm{kg}^{-1}$. The soil was passed through a $1-\mathrm{mm}$ sieve. Five radish plants were planted in a plastic bucket filled with $13-\mathrm{kg}$ soil samples for $30 \mathrm{~d}$. The $\mathrm{Cd}$ growing conditions were simulated by applying $\mathrm{CdCl}_{2} \cdot 2.5 \mathrm{H}_{2} \mathrm{O}$ to deionized fresh water at three concentrations of $0,1.0$, and $5.0 \mathrm{mg}(\mathrm{Cd}) \mathrm{kg}^{-1}$. The same amount of fertilizer was applied to all samples at a rate of $0.20 \mathrm{~g}(\mathrm{~N}), 0.07 \mathrm{~g}(\mathrm{P})$, and $0.17 \mathrm{~g}(\mathrm{~K})$. Three replicates were performed for each treatment. Plants were harvested after $30 \mathrm{~d}$ (at the seedling stage) and separated into root and leaf samples, which were washed three times with tap water, distilled water, and deionized water. For the physiological tests, the fresh samples were initially required to be stored in liquid nitrogen.

Gas-exchange parameters and $\mathrm{Chl}$ fluorescence: The net photosynthetic rate $\left(P_{\mathrm{N}}\right)$, stomatal conductance $\left(g_{\mathrm{s}}\right)$, and intercellular $\mathrm{CO}_{2}$ concentration $\left(C_{\mathrm{i}}\right)$ of the fully expanded leaves after $30 \mathrm{~d}$ following transplantation were recorded using an infra-red gas analyzer (IRGA, $\mathrm{Li}$-Cor, $\mathrm{Li}-6400$, Lincoln, NE, USA) from 9:00 to 11:00 h.

Chl fluorescence was measured using an integrative fluorescence fluorometer ( $\mathrm{Li}$-6400 leaf chamber fluorometer, $\mathrm{Li}$-Cor, USA). Following 1-h adaptation to darkness, the minimal Chl fluorescence $\left(\mathrm{F}_{0}\right)$ was determined using an intensity of $0.2 \mu \mathrm{mol}$ (photon) $\mathrm{m}^{-2} \mathrm{~s}^{-1}$. A saturation pulse [red and blue light of 7,200 $\mu \mathrm{mol}$ (photon) $\mathrm{m}^{-2} \mathrm{~s}^{-1}$ ] was used to obtain the maximal fluorescence $\left(\mathrm{F}_{\mathrm{m}}\right)$. The leaves were subsequently illuminated with actinic light $[1,400$ $\mu \mathrm{mol}\left(\right.$ photon) $\mathrm{m}^{-2} \mathrm{~s}^{-1}$ ] for $1 \mathrm{~h}$, The steady-state value of fluorescence $\left(\mathrm{F}_{\mathrm{s}}\right)$ was recorded and a second saturation pulse of $6,000 \mu \mathrm{mol}$ (photon) $\mathrm{m}^{-2} \mathrm{~s}^{-1}$ was imposed to determine the maximum fluorescence at the light-saturated stage $\left(\mathrm{F}_{\mathrm{m}}{ }^{\prime}\right)$, The actinic light was then removed and the minimal fluorescence at the light-saturated stage $\left(\mathrm{F}_{0}{ }^{\prime}\right)$ was determined by illuminating the leaves with far-red light [7 $\mu \mathrm{mol}$ (photon) $\mathrm{m}^{-2} \mathrm{~s}^{-1}$. Other fluorescence parameters [quantum yield of PSII photochemistry $\left(\Phi_{\text {PSII }}\right)$, electron transport rate through PSII (ETR), photochemical quenching $\left(\mathrm{q}_{\mathrm{P}}\right)$, and nonphotochemical quenching $\left.\left(\mathrm{q}_{\mathrm{N}}\right)\right]$ were calculated as described by Genty et al. (1989) and Maxwell and Johnson (2000).

Malondialdehyde (MDA): The concentration of MDA was determined by the thiobarbituric acid (TBA) reaction as described by Li et al. (2000) and Farooq et al. (2013). Fresh leaf samples $(0.50 \mathrm{~g})$ were homogenized in $5 \mathrm{ml}$ of $10 \%$ trichloroacetic acid. The homogenate was centrifuged at $12,000 \times g$ for $15 \mathrm{~min}$, and $1.5 \mathrm{ml}$ of the supernatant was mixed with $2.5 \mathrm{ml}$ of $0.5 \%$ 2-thiobarbituric acid. The absorbance was measured at 600,532 , and $450 \mathrm{~nm}$ (UV-5200, Shanghai Meipuda Instrument Co. Ltd., China).

Enzyme activities: The leaf samples were homogenized in $5 \mathrm{ml}$ of potassium phosphate buffer $(\mathrm{pH} \mathrm{7.0)}$, and the homogenate was then centrifuged at $12,000 \times g$ for $15 \mathrm{~min}$ at $4^{\circ} \mathrm{C}$, after which the supernatant was used for the following enzyme assays. The content of soluble protein and activities of SOD (EC 1.15.1.1), CAT (EC 1.11.1.6), and POD (EC 1.11.1.7) were estimated according to the method described by Li et al. (2000).

The reaction mixture contained $0.05 \mathrm{ml}$ of potassium phosphate buffer ( $\mathrm{pH} 7.8$ ), $0.3 \mathrm{ml}$ of $0.13 \mathrm{M}$ methionine, $0.3 \mathrm{ml}$ of $0.75 \mu \mathrm{M}$ nitroblue tetrazolium (NBT), $0.3 \mathrm{ml}$ of $0.1 \mu \mathrm{M}$ EDTA, $0.3 \mathrm{ml}$ of $0.02 \mu \mathrm{M}$ riboflavin, $0.25 \mathrm{ml}$ of distilled water, and $0.05 \mathrm{ml}$ of supernatant. The SOD activity was estimated as the quantity of enzyme required to cause a $50 \%$ inhibition in the reduction of NBT at $560 \mathrm{~nm}$ (UV-5200, Shanghai Meipuda Instrument Co. Ltd., China).

For CAT activity, the reaction mixture contained $1.5 \mathrm{ml}$ of potassium phosphate buffer $(\mathrm{pH} 7.0), 0.1 \mathrm{ml}$ of $0.1 \mathrm{M}$ $\mathrm{H}_{2} \mathrm{O}_{2}, 1.0 \mathrm{ml}$ of distilled water, and $0.2 \mathrm{ml}$ of enzyme extract. The CAT activity was estimated by monitoring the decrease of absorbance at $240 \mathrm{~nm}$ as the $\mathrm{H}_{2} \mathrm{O}_{2}$ was consumed (UV-5200, Shanghai Meipuda Instrument Co. Ltd., China). One unit of CAT activity was defined as $\mathrm{U} \mathrm{g}^{-1}$ (protein) $\mathrm{min}^{-1}$. 
For POD activity, the reaction mixture contained $2.9 \mathrm{ml}$ of extraction buffer ( $\mathrm{pH} 5.5$ ), $1.0 \mathrm{ml}$ of $2 \% \mathrm{H}_{2} \mathrm{O}_{2}, 1.0 \mathrm{ml}$ of guaiacol $(0.05 \mathrm{M})$, and $0.1 \mathrm{ml}$ of supernatant. The POD activity was calculated from the increase in absorbance $(470 \mathrm{~nm})$ due to the oxidation of guaiacol (UV-5200, Shanghai Meipuda Instrument Co. Ltd., China). The activity was expressed as $\mathrm{U} \mathrm{g}^{-1}$ (protein) $\mathrm{min}^{-1}$.

AsA and GSH: The leaf samples were homogenized in $5 \%$ metaphosphoric acid (w/v) and centrifuged at 12,000 $\times g$ for $15 \mathrm{~min}$ at $4^{\circ} \mathrm{C}$. The supernatant was collected for AsA and GSH analysis. The AsA was spectrophotometrically (UV-5200, Shanghai Meipuda Instrument Co. Ltd., China) quantified at $525 \mathrm{~nm}$ according to Mohamed et al. (2012). The assay mixture containing $150 \mathrm{mM}$ $\mathrm{NaH}_{2} \mathrm{PO}_{4}, \quad 10 \% \quad \mathrm{TCA}, 44 \% \quad \mathrm{H}_{3} \mathrm{PO}_{4}, 4 \% \quad 2,2^{\prime}$-dipyridyl $(\mathrm{w} / \mathrm{w})$, and $3 \% \mathrm{FeCl}_{3}$ was incubated at $37^{\circ} \mathrm{C}$ for $60 \mathrm{~min}$. The content was expressed in $\mathrm{mg} \mathrm{g}^{-1}(\mathrm{FM})$. The GSH was estimated by the method of Anderson (1985). It is based on the absorbance of the supernatant at $412 \mathrm{~nm}(U V-5200$, Shanghai Meipuda Instrument Co. Ltd., China). The assay mixture contained $150 \mathrm{mM} \mathrm{NaH} \mathrm{PO}_{4}$ and $4 \mathrm{mM}$ DNTP. The content was expressed in $\mathrm{mg} \mathrm{g}^{-1}(\mathrm{FM})$.

Statistical analysis: The data were analyzed using SPSS 20.0 software. The differences between cultivars were examined by one-way analysis of variance (ANOVA) followed by Duncan's multiple range test. The significant differences between means were tested at a probability $p \leq 0.05$. Figures were created using Sigma Plot ${ }^{T M}$ v. 10 .

\section{Results}

Biomass of the two radish cultivars: The exposure to different $\mathrm{Cd}$ concentrations caused variable effects on shoot, root, and total biomass of the two cultivars (Table 1). In $\mathrm{L} 19$, the shoot biomass at the $1.0 \mathrm{mg}(\mathrm{Cd}) \mathrm{kg}^{-1}$ was $37 \%$ higher than that of control, which resulted in the aboveground biomass being significantly enhanced compared with the control; however, the aboveground biomass at the $5.0 \mathrm{mg}(\mathrm{Cd}) \mathrm{kg}^{-1}$ was basically the same as that of control. In contrast to L19, the shoot and total biomass of $\mathrm{H} 4$ significantly decreased at $5.0 \mathrm{mg}(\mathrm{Cd})$ $\mathrm{kg}^{-1}$, the reduction was $24 \%$ compared to the control. No significant variations between the shoot and root under the
$1.0 \mathrm{mg}(\mathrm{Cd}) \mathrm{kg}^{-1}$ and control treatments were observed. When subjected to $\mathrm{Cd}$ stress, the range of root biomass in the same radish cultivar was lesser than that of the aboveground biomass. It indicated that the inhibition of shoot growth by $\mathrm{Cd}$ stress is more serious than that for roots and the growth of L19 was promoted by the low $\mathrm{Cd}$ concentration.

Gas-exchange parameters of the two radish cultivars: The $P_{\mathrm{N}}$ of both cultivars decreased, while $C_{\mathrm{i}}$ increased with the increasing $\mathrm{Cd}$ concentrations (Fig. 1). In comparison with the control, the declines in $P_{\mathrm{N}}$ were $2 \%$ in L19 and $22 \%$ in $\mathrm{H} 4$ at $5.0 \mathrm{mg}(\mathrm{Cd}) \mathrm{kg}^{-1}$, respectively. Moreover, the $P_{\mathrm{N}}$ of $\mathrm{L} 19$ was 7 and $23 \%$ higher than that of $\mathrm{H} 4$ at the 1.0 and $5.0 \mathrm{mg}(\mathrm{Cd}) \mathrm{kg}^{-1}$; however, there were no significant differences in $g_{\mathrm{s}}$ and $C_{\mathrm{i}}$ between the two cultivars. It indicated that the photosynthetic rate of both radish cultivars was lowered; however, $C_{\mathrm{i}}$ was improved by $\mathrm{Cd}$ exposure.

Chl fluorescence parameters of the two radish cultivars: $\Phi_{\mathrm{PSII}}, \mathrm{ETR}$, and $\mathrm{q}_{\mathrm{P}}$ of the two cultivars were reduced, whereas $\mathrm{q}_{\mathrm{N}}$ increased with the increase in the $\mathrm{Cd}$ concentration (Fig. 2). No significant differences in the $\Phi_{\text {PSII }}$, ETR, $\mathrm{q}_{\mathrm{P}}$, and $\mathrm{q}_{\mathrm{N}}$ in L19 were observed between the different $\mathrm{Cd}$ treatments. For $\mathrm{H} 4$ cultivar, $\Phi_{\mathrm{PSII}}, \mathrm{ETR}, \mathrm{q}_{\mathrm{P}}$, and $\mathrm{q}_{\mathrm{N}}$ at the $1.0 \mathrm{mg}(\mathrm{Cd}) \mathrm{kg}^{-1}$ were statistically the same as the control; however, $\Phi_{\text {PSII }}$, ETR, and $\mathrm{q}_{\mathrm{P}}$ at the $5.0 \mathrm{mg}(\mathrm{Cd})$ $\mathrm{kg}^{-1}$ were significantly reduced by 35,35 , and $18 \%$, respectively, compared with control, while $\mathrm{q}_{\mathrm{N}}$ significantly increased by $36 \%$.

MDA concentration of the two radish cultivars: Formation of MDA is considered as a measure of lipid peroxidation in plants. The MDA concentration in leaves of the two cultivars increased obviously with the increasing $\mathrm{Cd}$ concentrations (Fig. $3 \mathrm{~A}$ ). The MDA content in $\mathrm{H} 4$ increased by 16 and $49 \%$ at 1.0 and $5.0 \mathrm{mg}(\mathrm{Cd}) \mathrm{kg}^{-1}$, respectively, while the increases were just 4 and $20 \%$ for L19, respectively, in comparison with the control. The MDA concentrations of $\mathrm{H} 4$ were 8 and $20 \%$ higher than that of $\mathrm{L} 19$ under the 1.0 and $5.0 \mathrm{mg}(\mathrm{Cd}) \mathrm{kg}^{-1}$, respectively.

Antioxidant systems of the two radish cultivars: With exposure to Cd, CAT activity was not significantly affected in L19 and H4, although CAT activities of L19

Table 1. Effect of Cd concentrations on biomass of the two radish cultivars. Values are means \pm SE $(n=3)$. Values followed by different letters indicate significant differences followed by Duncan's test $(p \leq 0.05)$ for both cultivars at different Cd treatments. DM indicates dry mass.

\begin{tabular}{|c|c|c|c|c|}
\hline Cultivar & $\begin{array}{l}\text { Cd content } \\
{\left[\mathrm{mg} \mathrm{kg}^{-1}\right]}\end{array}$ & $\begin{array}{l}\text { Shoot biomass } \\
\text { [g(DM) per plant }]\end{array}$ & $\begin{array}{l}\text { Root biomass } \\
{[\mathrm{g}(\mathrm{DM}) \text { per plant }]}\end{array}$ & $\begin{array}{l}\text { Total biomass } \\
{[\mathrm{g}(\mathrm{DM}) \text { per plant }]}\end{array}$ \\
\hline \multirow[t]{3}{*}{ L19 } & 0 & $2.09 \pm 0.06^{\mathrm{cd}}$ & $0.20 \pm 0.03^{\mathrm{b}}$ & $2.29 \pm 0.08^{c}$ \\
\hline & 1.0 & $2.87 \pm 0.13^{\mathrm{a}}$ & $0.28 \pm 0.03^{b}$ & $3.14 \pm 0.10^{\mathrm{a}}$ \\
\hline & 5.0 & $2.26 \pm 0.15^{\mathrm{bc}}$ & $0.32 \pm 0.03^{\mathrm{b}}$ & $2.52 \pm 0.19^{b c}$ \\
\hline \multirow[t]{3}{*}{$\mathrm{H} 4$} & 0 & $2.49 \pm 0.08^{\mathrm{b}}$ & $1.03 \pm 0.15^{\mathrm{a}}$ & $3.39 \pm 0.24^{\mathrm{a}}$ \\
\hline & 1.0 & $2.39 \pm 0.06^{\mathrm{abc}}$ & $1.24 \pm 0.10^{\mathrm{a}}$ & $3.44 \pm 0.18^{\mathrm{a}}$ \\
\hline & 5.0 & $1.88 \pm 0.09^{\mathrm{d}}$ & $1.05 \pm 0.04^{\mathrm{a}}$ & $2.93 \pm 0.13^{\mathrm{ab}}$ \\
\hline
\end{tabular}




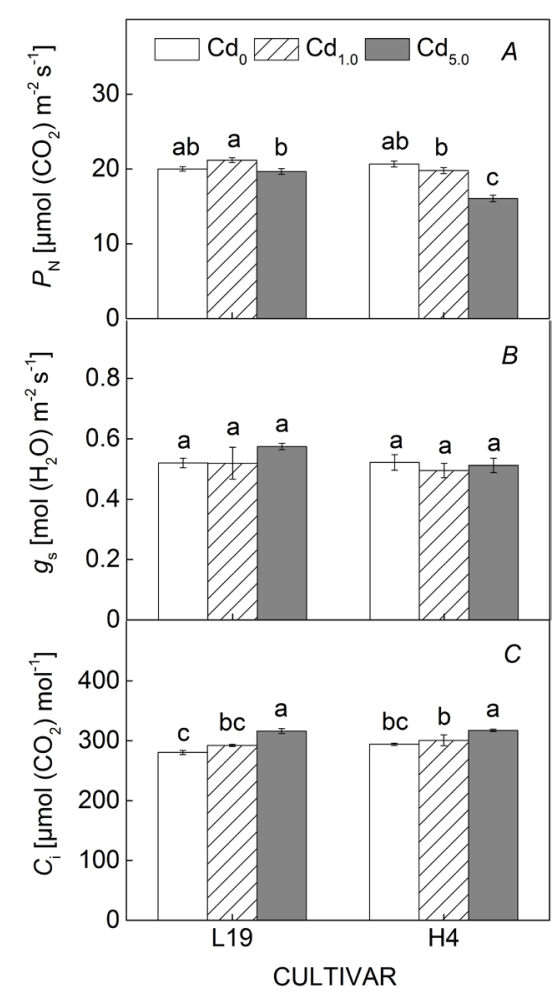

Fig. 1. Effect of $\mathrm{Cd}$ concentrations on net photosynthetic rate $\left(P_{\mathrm{N}}\right)(A)$, stomatal conductance $\left(g_{\mathrm{s}}\right)(B)$, and intercellular $\mathrm{CO}_{2}$ concentration $\left(C_{\mathrm{i}}\right)(C)$ of the two radish cultivars leaves. Values are means $\pm \mathrm{SE}(n=3)$. The bars with different letters between the two cultivars at the different $\mathrm{Cd}$ concentrations denote significant differences at $p \leq 0.05$.

were 35,33 , and $7 \%$ higher than that of $\mathrm{H} 4$ at $0,1.0$, and $5.0 \mathrm{mg}(\mathrm{Cd}) \mathrm{kg}^{-1}$, respectively (Fig. $3 B-D$ ). The POD activity of L19 remarkably increased with the increasing $\mathrm{Cd}$ concentrations, whereas POD activity of $\mathrm{H} 4$ was initially enhanced at the $1.0 \mathrm{mg}(\mathrm{Cd}) \mathrm{kg}^{-1}$ and then decreased at $5.0 \mathrm{mg}(\mathrm{Cd}) \mathrm{kg}^{-1}$. Further, the POD activities of L19 were 74,36 , and $102 \%$ higher than that of $\mathrm{H} 4$ at the three Cd treatments. The SOD activities of both cultivars revealed a trend that was similar to the POD activity of $\mathrm{H} 4$; however, there were no significant differences between the two cultivars at all the $\mathrm{Cd}$ treatments.

AsA concentrations in leaves of both cultivars were significantly reduced with increasing $\mathrm{Cd}$ concentrations, while the reduction was sharper in L19 (Fig. 4A). Meanwhile, the AsA concentration was obviously higher in L19 than that of $\mathrm{H} 4$ at 0 and $1.0 \mathrm{mg}(\mathrm{Cd}) \mathrm{kg}^{-1}$, whereas there was no significant difference at $5.0 \mathrm{mg}(\mathrm{Cd}) \mathrm{kg}^{-1}$ between the two cultivars. No significant differences between treatments were found in GSH concentration of L19, while the GSH concentration of H4 was significantly higher at $1.0 \mathrm{mg}(\mathrm{Cd}) \mathrm{kg}^{-1}$ compared to the other two treatments (Fig. 4B).

\section{Discussion}

It has been reported that the photosynthesis and antioxidant defense systems are very sensitive to Cd stress (Xue et al.
2014). Plant species and genotypes obviously differ in their photosynthesis, antioxidant enzymatic activities, and antioxidant substances under Cd stress (Mobin and Khan 2007, Zayneb et al. 2015).

Generally, photosynthesis can be affected by stomatal and nonstomatal limitations (Farquhar and Sharkey 2003, He et al. 2016). In our study, elevated concentrations of $\mathrm{Cd}$ were found to decrease the $P_{\mathrm{N}}$ in both radish cultivars, which was accompanied with an increase of $C_{\mathrm{i}}$ and unchanged $g_{\mathrm{s}}$. The increase of $C_{\mathrm{i}}$ indicates that the decrease of $P_{\mathrm{N}}$ might be primarily attributed to nonstomatal limitations, such as damages to the photosynthetic apparatus and/or inhibitory effects of the Calvin cycle enzymatic activities and PSII electron transport (Parmar et al. 2013). Tóth et al. (2012) reported that Cd could inhibit the dark phase of the photosynthesis via specific binding to enzymes of the Calvin cycle and/or that involved in the carbon concentrating mechanism (CCM) Vitória et al. (2006) used radish as experimental material and found that chloroplasts from Cd-exposed samples exhibited alterations in organelle morphology, an increase in the stroma volume, and the deposition of electron-dense material within the double membrane. $P_{\mathrm{N}}$ directly affects photosynthetic products, and photosynthetic products are the main sources for biomass production. In $\mathrm{H} 4$, the decrease in shoot biomass might be attributed to the more rapid decline of $P_{\mathrm{N}}$ with increasing Cd concentrations. On the contrary, the shoot biomass of L19 was promoted at the low Cd concentration, along with the mild increase of $P_{\mathrm{N}}$. Furthermore, Cd concentrations in shoots and roots of H4 were all significantly higher than that of L19 (Xin et al. 2017). These facts demonstrate that L19 is more resistant to Cd exposure than H4. Similar results have been reported by Jin et al. (2008), who compared Cd-hyperaccumulator (HE) and non-Cd-hyperaccumulator ecotypes (NHE) and reported that the shoot and root biomass of NHE decreased significantly, but those of HE increased significantly with Cd stress.

Chl fluorescence analysis has become a probe for photosynthesis in vivo, which can quickly identify the potential causes of changes in photosynthesis and plant performance (Baker 2008). Żurek et al. (2014) reported that Chl fluorescence was closely related to the photosynthetic electron transfer chain and further biochemical processes. Roháček (2002) and Lazár (2015) found that $\mathrm{q}_{\mathrm{P}}$ reflects activation of the photochemical processes, estimating a fraction of open PSII reaction centers, whereas $\mathrm{q}_{\mathrm{N}}$ reflects activation of the nonphotochemical processes, leading mostly to the nonradiative energy dissipation as heat. In our study, $\Phi_{\text {PSII }}$, ETR, and $\mathrm{q}_{\mathrm{p}}$ in $\mathrm{H} 4$ were obviously reduced, whereas $\mathrm{q}_{\mathrm{N}}$ increased with the increasing $\mathrm{Cd}$ concentrations, which might account for a decrease of biomass and $P_{\mathrm{N}}$ in H4. The decrease of ETR indicated that reoxidation of $\mathrm{Q}_{\mathrm{A}}$ was limited by the partial block of electron transport from PSII to PSI (Ekmekçi et al. 2008). The reduction of $\Phi_{\mathrm{PSII}}$ and $\mathrm{q}_{\mathrm{P}}$, as well as the increase of $\mathrm{q}_{\mathrm{N}}$, suggested that less light energy was utilized by photochemical reactions, while less excessive excited energy was produced under Cd treatments (Xue et al. 2014). These results are in agreement with Xue et al. (2018) and 


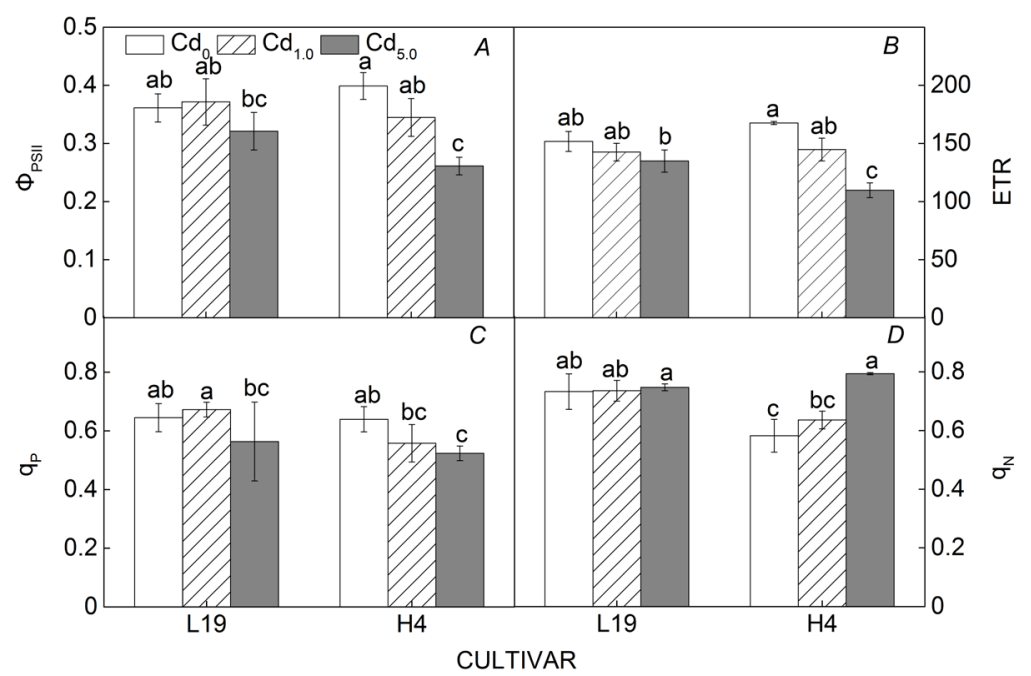

Fig. 2. Effect of $\mathrm{Cd}$ concentrations on quantum yield of PSII photochemistry $\left(\Phi_{\mathrm{PSII}}\right)(A)$, electron transport rate through PSII (ETR) $(B)$, photochemical quenching $\left(\mathrm{q}_{\mathrm{P}}\right)(C)$, and nonphotochemical quenching $\left(\mathrm{q}_{\mathrm{N}}\right)(D)$ of the two radish cultivars leaves. Values are means $\pm \operatorname{SE}(n=3)$. The bars with different letters between the two cultivars at the different $\mathrm{Cd}$ levels denote significant differences at $p \leq 0.05$.

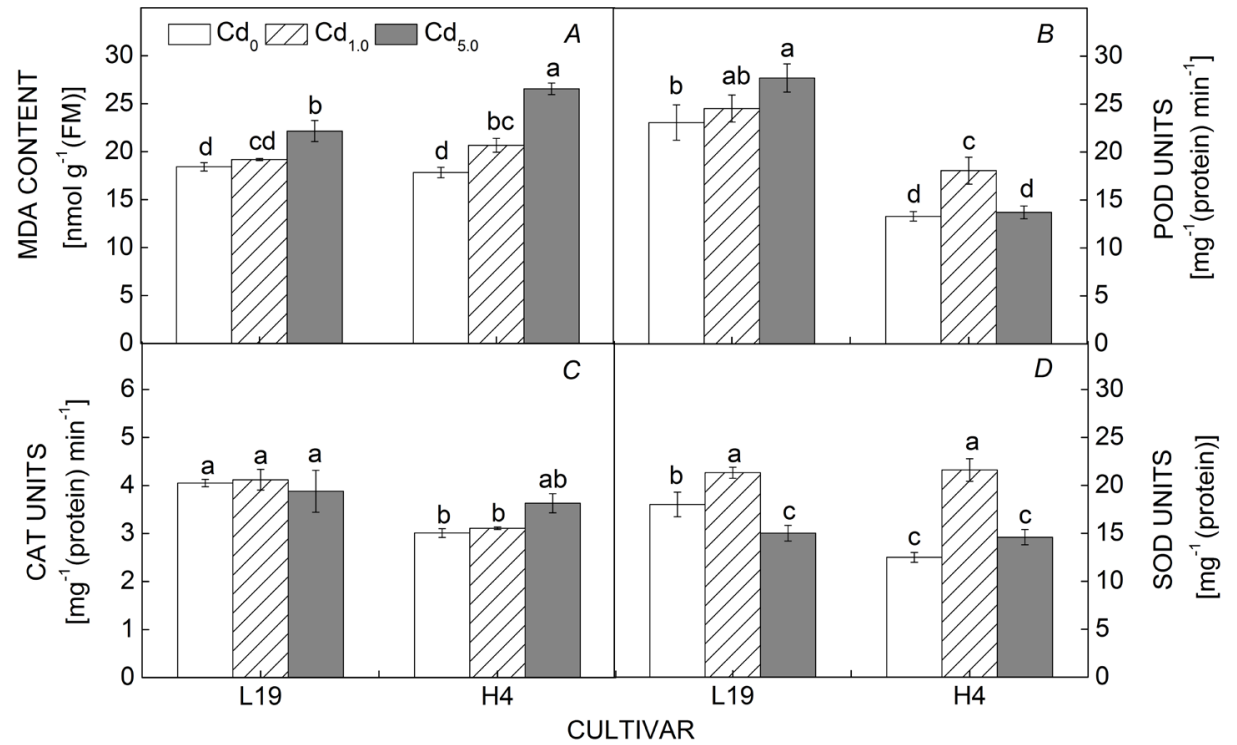

Fig. 3. Effect of Cd concentrations on malondialdehyde (MDA) content $(A)$, peroxidase (POD) $(B)$, catalase (CAT) $(C)$, and superoxide dismutase (SOD) $(D)$ activities of the two radish cultivars leaves. Values are means $\pm \mathrm{SE}(n=3)$. The bars with different letters between the two cultivars at the different $\mathrm{Cd}$ concentrations denote significant differences at $p \leq 0.05$.

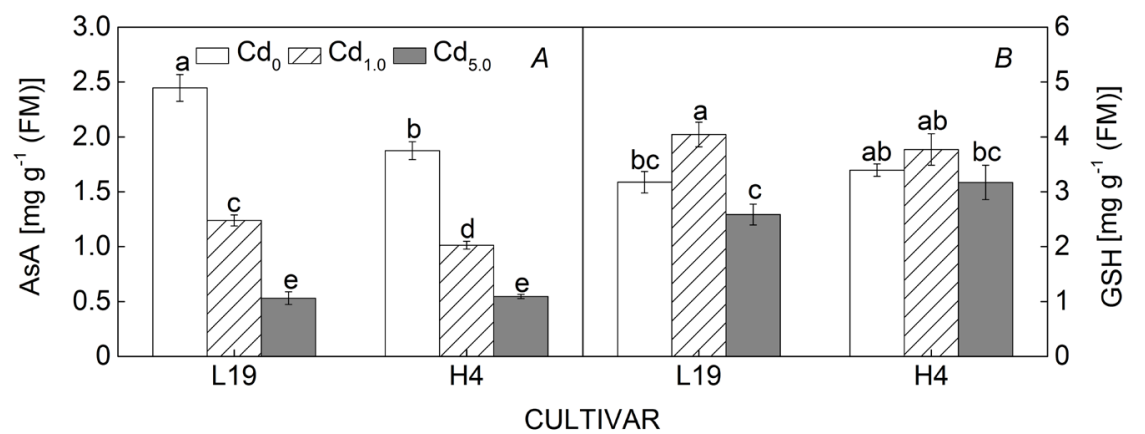

Fig. 4. Effect of Cd concentrations on ascorbic acid (AsA) $(A)$ and reduced glutathione (GSH) $(B)$ content of the two radish cultivars leaves. Values are means $\pm \mathrm{SE}(n=3)$. The bars with different letters between the two cultivars at the different Cd concentrations denote significant differences at $p \leq 0.05$. 
Ekmekçi et al. (2008), who suggested that plants would suffer photoinhibition due to reversible inactivation or destruction of the PSII reaction center under $\mathrm{Cd}$ exposure. For L19, no significant differences were observed in $\Phi_{\text {PSII, }}$, ETR, $\mathrm{q}_{\mathrm{p}}$, and $\mathrm{q}_{\mathrm{N}}$, which resulted in no significant changes of $P_{\mathrm{N}}$ compared with the control.

In chloroplasts, electron transport chains (ETCs) of PSI and PSII serve as the primary sources of ROS, which are activated by Cd stress (Foyer et al. 1994). Sharma et al. (2012) indicated that ETCs in PSI and PSII are the main sources of ROS in chloroplasts. Production of ROS by these sources is enhanced in plants by conditions limiting $\mathrm{CO}_{2}$ fixation, such as drought, salt, and temperature stresses. MDA is a final product of membrane lipid peroxidation by ROS. In the present study, the MDA content in leaves of H4 was higher than that of L19 at any $\mathrm{Cd}$ concentration. This result shows that $\mathrm{H} 4$ experiences a greater oxidative damage than L19. Our result is in agreement with Shi et al. (2010) and Xu et al. (2012), who reported that cell membrane could suffer more extensive damage when exposed to high Cd concentrations. Pospíšil et al. (2012) reported that an efficient antioxidant defense system plays a critical role in scavenging excessive ROS and maintaining redox balance. POD, CAT, and SOD are universally present antioxidant enzymes in various cellular compartments. Studies have shown that both increases and reductions in enzymatic activities were observed in response to Cd exposure (Mohamed et al. 2012, Shu et al. 2012, Liu et al. 2018). In our study, POD activity of H4 and CAT activities of both cultivars exhibited an increase at low $\mathrm{Cd}$ concentrations and a reduction at high $\mathrm{Cd}$ concentrations. The increase in POD and CAT activities of both cultivars might be a result of both stimulation by Cd stress, as well as an increase in substrate contents (Tanyolaç et al. 2007). The reduction in POD activity of $\mathrm{H} 4$ and CAT activities of both cultivars observed at $5.0 \mathrm{mg}(\mathrm{Cd}) \mathrm{kg}^{-1}$ might be explained by a decrease in enzyme synthesis and/or changes in assembly of its subunits (Verma and Dubey 2003). Further, L19 exhibited higher POD and CAT activity in contrast to H4 at any $\mathrm{Cd}$ treatment. This indicates that L19 is more efficient in avoiding oxidative damage from heavy metal.

Low molecular antioxidants such as AsA and GSH are required to protect plant from oxidative stress. In the present study, AsA was reduced significantly by $\mathrm{Cd}$ stress. This might be caused due to the following potential mechanisms: (1) directly, through the combination with heavy metals, which further prevented their transmembrane transport; (2) indirectly, by acting as a reducing agent, protecting thiol-containing proteins and enzymes in cell membranes from oxidation (Rai 1979). In contrast to what was reported for AsA, Cd induced the increase of $\mathrm{GSH}$ at low $\mathrm{Cd}$ concentration and reduction at high $\mathrm{Cd}$ concentration. The increased formation of GSH might comprise 'truly adaptive responses' in response to Cd stress. Moreover, GSH is not only known as general reductant but also serves as substrate participating in control of ROS levels (Xu et al. 2016). Hence, the decrease of GSH might be ascribed to its role as an antioxidant or metal chelator involved in Cd tolerance. Compared to L19, the smaller reduction of AsA and unchanged GSH were observed in $\mathrm{H} 4$. These indicate that $\mathrm{H} 4$ exhibited higher AsA and GSH synthetic capacities which was beneficial for its tolerance to $\mathrm{Cd}$ toxicity. Similar results were obtained by $\mathrm{Wu}$ et al. (2004) and Mohamed et al. (2012).

In conclusion, L19 was more tolerant to $\mathrm{Cd}$ stress compared to H4. In the present study, a significant increase was found in the biomass of L19 at the $1.0 \mathrm{mg}(\mathrm{Cd}) \mathrm{kg}^{-1}$, however, that of $\mathrm{H} 4$ decreased significantly at the 5.0 $\mathrm{mg}(\mathrm{Cd}) \mathrm{kg}^{-1}$. These differences could be a result of distinct photosynthetic and antioxidant system parameters in L19 and H4. In the future, we will continue with in-depth studies toward the elucidation of the relationship between photosynthesis and antioxidant systems in the leaves.

\section{References}

Anderson M.E.: Determination of glutathione and glutathione disulfide in biological samples. - Method. Enzymol. 113: 548-555, 1985.

Baker N.R.: Chlorophyll fluorescence: a probe of photosynthesis in vivo. - Annu. Rev. Plant Biol. 59: 89-113, 2008.

Daud M.K., Ali S., Variath M.T., Zhu S.J.: Differential physiological, ultramorphological and metabolic responses of cotton cultivars under cadmium stress. - Chemosphere 93: 25932602, 2013.

Dias M.C., Monteiro C., Moutinho-Pereira J. et al.: Cadmium toxicity affects photosynthesis and plant growth at different levels. - Acta Physiol. Plant. 35: 1281-1289, 2013.

Ekmekçi Y., Tanyolaç D., Ayhan B.: Effects of cadmium on antioxidant enzyme and photosynthetic activities in leaves of two maize cultivars. - J. Plant Physiol. 165: 600-611, 2008.

Farooq M.A., Ali S., Hameed A. et al.: Alleviation of cadmium toxicity by silicon is related to elevated photosynthesis, antioxidant enzymes; suppressed cadmium uptake and oxidative stress in cotton. - Ecotox. Environ. Safe. 96: 242-249, 2013.

Farquhar G.D., Sharkey T.D.: Stomatal conductance and photosynthesis. - Annu. Rev. Plant Physiol. 33: 317-345, 2003.

Foyer C.H., Descourvières P., Kunert K.J.: Protection against oxygen radicals: an important defence mechanism studied in transgenic plants. - Plant Cell Environ. 17: 507-523, 1994.

Genty B., Briantais J.M., Baker N.R.: The relationship between the quantum yield of photosynthetic electron transport and quenching of chlorophyll fluorescence. - BBA-Gen. Subjects 990: 87-92, 1989.

Grant C.A.: Influence of phosphate fertilizer on cadmium in agricultural soils and crops. - Pedologist 54: 143-155, 2011.

Hashem H.A.: Cadmium toxicity induces lipid peroxidation and alters cytokinin content and antioxidant enzyme activities in soybean. - Botany 92: 1-7, 2014.

He G.Q., Liu Q., Guo Z.N. et al.: [Effects of cadmium stress on photosynthetic and characteristics, chlorophyll fluorescence in leaves of flue-cured tobacco.] - Acta Agriculturae BorealiSinica 31: 388-393, 2016. [In Chinese]

Jin X.F., Yang X.E., Islam E. et al.: Effects of cadmium on ultrastructure and antioxidative defense system in hyperaccumulator and non-hyperaccumulator ecotypes of Sedum alfredii Hance. - J. Hazard. Mater. 156: 387-397, 2008.

Lazár D.: Parameters of photosynthetic energy partitioning. J. Plant Physiol. 175: 131-147, 2015.

Li H.S., Sun Q., Zhao S.J. et al.: [Principles and Techniques of Plant Physiological Biochemical Experiment.] Pp. 195-197. Higher Education Press, Beijing 2000. [In Chinese]

Liu Z.L., Chen W., He X.Y. et al.: Effects of low concentration 
cadmium on the growth and photosynthetic physiology of Lonicera japonica Thunb. - Environ. Chem. 37: 223-228, 2018.

Luo H., Li H., Zhang X., Fu J.: Antioxidant responses and gene expression in perennial ryegrass (Lolium perenne L.) under cadmium stress. - Ecotoxicology 20: 770-778, 2011.

Maxwell K., Johnson G.N.: Chlorophyll fluorescence a practical guide. - J. Exp. Bot. 51: 659-668, 2000.

Mesnoua M., Mateos-Naranjo E., Barcia-Piedras J.M. et al.: Physiological and biochemical mechanisms preventing Cdtoxicity in the hyperaccumulator Atriplex halimus L. - Plant Physiol. Bioch. 106: 30-38, 2016.

Mobin M., Khan N.A.: Photosynthetic activity, pigment composition and antioxidative response of two mustard (Brassica juncea) cultivars differing in photosynthetic capacity subjected to cadmium stress. - J. Plant Physiol. 164: 601-610, 2007.

Mohamed A.A., Castagna A., Ranieri A. et al: Cadmium tolerance in Brassica juncea roots and shoots is affected by antioxidant status and phytochelatin biosynthesis. - Plant Physiol. Bioch. 57: 15-22, 2012.

Namdjoyan S., Namdjoyan S., Kermanian H.: Induction of phytochelatin and responses of antioxidants under cadmium stress in safflower (Carthamus tinctorius) seedlings. - Turk. J. Bot. 36: 495-502, 2014.

Parmar P., Kumari N., Sharma V.: Structural and functional alterations in photosynthetic apparatus of plants under cadmium stress. - Bot. Stud. 54: 2757-2770, 2013.

Pereira de Araújo R., Furtado de Almeida A.A., Silva Pereira L. et al:: Photosynthetic, antioxidative, molecular and ultrastructural responses of young cacao plants to $\mathrm{Cd}$ toxicity in the soil. - Ecotox. Environ. Safe. 144: 148-157, 2017.

Pospíšil P.: Molecular mechanisms of production and scavenging of reactive oxygen species by photosystem II. - BBABioenergetics 1817: 218-231, 2012.

Pospíśil P.: The role of metals in production and scavenging of reactive oxygen species in photosystem II. - Plant Cell Physiol. 55: 1224-1232, 2014.

Rai L.C.: Mercuric chloride effect on Chlorella. I. Reversal of toxicity by ascorbic acid and reduced glutathione (GSH). Phykos 18: 105-109, 1979.

Roháček K.: Chlorophyll fluorescence parameters: the definitions, photosynthetic meaning, and mutual relationships. Photosynthetica 40: 13-29, 2002.

Sharma P., Jha A.B., Dubey R.S., Pessarakli M.: Reactive oxygen species, oxidative damage, and antioxidative defense mechanism in plants under stressful conditions. - J. Bot. 2012: 1-26, 2012.

Shi G., Liu C., Cai Q. et al.: Cadmium accumulation and tolerance of two safflower cultivars in relation to photosynthesis and antioxidantive enzymes. - B. Environ. Contam. Tox. 85: 256-263, 2010.

Shu X., Yin L., Zhang Q., Wang W.: Effect of Pb toxicity on leaf growth, antioxidant enzyme activities, and photosynthesis in cuttings and seedlings of Jatropha curcas L. - Environ. Sci. Pollut. R. 19: 893-902, 2012.

Tanyolaç D., Ekmekçi Y., Unalan S.: Changes in photochemical and antioxidant enzyme activities in maize (Zea mays L.) leaves exposed to excess copper. - Chemosphere 67: 89-98, 2007.

Tóth T., Zsiros O., Kis M. et al:: Cadmium exerts its toxic effects on photosynthesis via a cascade mechanism in the cyanobacterium, Synechocystis PCC 6803. - Plant Cell Environ. 35: 2075-2086, 2012.

Verma S., Dubey R.S.: Lead toxicity induces lipid peroxidation and alters the activities of antioxidant enzymes in growing rice plants. - Plant Sci. 164: 645-655, 2003.

Vitória A.P., da Cunha M., Azevedo R.A.: Ultrastructural changes of radish leaf exposed to cadmium. - Environ. Exp. Bot. 58: 47-52, 2006.

Wang L.Z., He Q.W.: [Chinese Radishes.] Pp. 1-6. Scientific and Technical Documents Publishing House, Beijing 2005. [In Chinese]

Wang Y., Jiang X., Li K. et al:: Photosynthetic responses of Oryza sativa L. seedlings to cadmium stress: physiological, biochemical and ultrastructural analyses. - Biometals 27: 389-401, 2014.

Wu F.B., Chen F., Wei K., Zhang G.P.: Effect of cadmium on free amino acid, glutathione and ascorbic acid concentrations in two barley genotypes (Hordeum vulgare L.) differing in cadmium tolerance. - Chemosphere 57: 447-454, 2004.

Xin J., Zhao X.H., Tan Q.L. et al.: Comparison of cadmium absorption, translocation, subcellular distribution and chemical forms between two radish cultivars (Raphanus sativus L.). - Ecotox. Environ. Safe. 145: 258-265, 2017.

Xu P., Zeng G.M., Huang D.L. et al:: Metal bioaccumulation, oxidative stress and antioxidant defenses in Phanerochaete chrysosporium response to $\mathrm{Cd}$ exposure. - Ecol. Eng. 87: 150-156, 2016.

Xu Q., Min H., Cai S. et al.: Subcellular distribution and toxicity of cadmium in Potamogeton crispus L. - Chemosphere 89: 114-120, 2012.

Xue Z., Gao H., Zhao S.: Effects of cadmium on the photosynthetic activity in mature and young leaves of soybean plants. Environ. Sci. Pollut. R. 21: 4656-4664, 2014.

Xue Z.C., Li J.H., Li D.S. et al.: Bioaccumulation and photosynthetic activity response of sweet sorghum seedling (Sorghum bicolor L. Moench) to cadmium stress. Photosynthetica 56: 1422-1428, 2018.

Zayneb C., Bassem K., Zeineb K. et al.: Physiological responses of fenugreek seedlings and plants treated with cadmium. Environ. Sci. Pollut. R. 22: 10679-10689, 2015.

Żurek G., Rybka K., Pogrzeba M. et al:: Chlorophyll a fluorescence in evaluation of the effect of heavy metal soil contamination on perennial grasses. - PLoS ONE 9: 91475, 2014.

(C) The authors. This is an open access article distributed under the terms of the Creative Commons BY-NC-ND Licence. 